\title{
AVALIAÇÃO DO POTENCIAL REPRODUTIVO DO CORRUPTO CALLICHIRUS MAJOR (SAY, 1818) (CRUSTACEA, CALLIANASSIDAE) NA PRAIA DA ENSEADA, EM SÃO FRANCISCO DO SUL-SC
}

\author{
Miranda, L.M. ${ }^{1}{ }^{*}$, Rodrigues, L.R. ${ }^{1}$; Costa, J.R.P. ${ }^{1}$; Nunes, J.S. ${ }^{1}$; \\ Brito, G.A. ${ }^{1}$; Pantaleão, J.A.F. ${ }^{2}$ \& Andrade, L.S. ${ }^{1}$ \\ ${ }^{1}$ Universidade Federal do Triângulo Mineiro (UFTM), Campus Iturama, \\ Grupo de Ensino, Pesquisa e Extensão em Animais Aquáticos (GEPEAA). \\ ${ }^{2}$ Universidade Federal do Triângulo Mineiro (UFTM), Campus Uberaba, GEPEAA. \\ *Autor correspondente: lubiamaciel@hotmail.com
}

\begin{abstract}
Popularmente conhecido como corrupto, Callichirus major é a espécie mais abundante e de maior distribuição espacial nas praias dissipativas do litoral brasileiro. Esse crustáceo de hábito recluso apresenta importante papel nos ecossistemas de praias devido à sua atividade bioturbadora, a qual influência nas propriedades físicas e químicas do sedimento. Tais animais são vastamente utilizados como isca ao longo das praias oceânicas do litoral brasileiro, prática que pode levar à sobre-exploração do recurso e até ao total desaparecimento das populações alvo. O conhecimento da fecundidade de C. major permite avaliar a estabilidade da população frente aos impactos constantes da coleta descontrolada desses animais, bem como estimar o potencial reprodutivo e o tamanho da unidade populacional da população natural. O objetivo desse trabalho foi estimar a fecundidade da população do corrupto C. major encontrada ao longo da Praia da Enseada, São Francisco do Sul-SC. Os animais foram coletados durante o mês de janeiro, alta temporada, com a utilização de uma bomba aspirante simples. As fêmeas que portavam ovos foram individualizadas em tubetes e fixadas em álcool $70 \%$. No laboratório de microscopia da UFTM, campus Iturama, foram mensurados o comprimento cefalotorácico (CC) de 20 animais. Os ovos portados foram desprendidos da região abdominal e contados. A quantidade de ovos foi relacionada ao tamanho do CC da fêmea que os portava, por meio de ajuste de uma regressão linear. O tamanho das fêmeas variou entre 10,2 a 18,9 mm CC, com tamanho médio de 14,09 $\pm 2,38$ mm CC. A menor massa de ovos continha 223 unidades, e foi encontrada em uma fêmea de 10,2 mm CC. Já a maior massa, com 4778 ovos era proveniente de uma fêmea de 18,9 mm CC. O número médio de ovos em cada massa foi de 2302,9 $\pm 1380,5176$. A análise de regressão revelou uma relação significativa $(r=0,44, p<0,01)$ entre o comprimento cefalotorácico e o número de ovos portados pela fêmea, sendo possível concluir que quanto maior o CC, maior será o número de ovos portados por fêmeas, uma vez que p é menor que 0,05.
\end{abstract}

Palavras-chave: fecundidade, Thalassinidea, reprodução. 